\title{
Building an Attitude Scale about E-learning among Isra University Students according to the Item Response Theory in Measurement
}

\author{
Mohammad Al-Dlalah ${ }^{1}$, Hani Alkhaldi ${ }^{1}$, Malek Alkhutaba ${ }^{2}$ \& Taghreed Al-Momani ${ }^{3}$ \\ ${ }^{1}$ Department of Teacher Education, Isra University, Jordan \\ ${ }^{2}$ Department of Psychology, Isra University, Jordan \\ ${ }^{3}$ Curriculum and Instruction in Mathematics Education, Amman, Jordan \\ Correspondence: Malek Alkhutaba, Department of Psychology, Isra University, Amman, Jordan.
}

Received: October 4, 2020

doi:10.5430/ijhe.v10n2p188
Accepted: November 30, $2020 \quad$ Online Published: December 4, 2020

URL: https://doi.org/10.5430/ijhe.v10n2p188

\begin{abstract}
Nowadays, E-learning is one of the most inevitable technique and learning approach, because it offers indispensable advancement of the education process. Furthermore, it supports and enhances many facets of the learning process. This study aimed to build an attitude scale about e-learning among Isra University students according to the item response theory (IRT) in measurement. To achieve the study's objectives, the main dimensions of the scale were identified, and 44 items were unevenly formatted. The tool was applied to 550 students who were social media users at Isra University. After analyzing the participants' responses according to IRT, the final form of the scale consisted of 29 items that were divided into three main dimensions. The reliability of the scale was $0.94 \%$, while the scale had multiple indications of validation.
\end{abstract}

Keywords: e-learning, attitude scale, Item Response Theory in measurement, IRT

\section{Introduction}

University-level educational programs and methods for development are crucial because universities are considered one of the main pillars contributing to the advancement of society. Because of accelerated technological advancement that encompasses all walks of life, particularly education, it is important to emphasize e-learning. COVID-19, which swept the world and forced it to withdraw temporarily from traditional teaching methods, placed further importance on e-learning while implementing safety and prevention procedures for COVID-19. E-learning is a highly supportive tool and can transform traditional teaching methods by promoting creativity and increasing the interaction and skills used to communicate information with high accuracy and flexibility (Shahada, 2006).

E-learning advances various areas of education by using the most modern methods of information and communications technology. Rapid technological advancement has led to the emergence of new learning styles and patterns, further entrenching the concept and availability of individual or self-education. Students learn based on their energy, ability, experience, and skills. E-learning relies mainly on transfer of knowledge and skills by presenting lesson content online or via audio tapes, videos, and compact discs. E-learning programs also allow exams and research papers to be sent via applications, programs, and emails, and questions and answers can be addressed electronically. It also provides continuous constructive evaluation and immediate feedback, which help improve student achievement (Al-Momani \& Dlalah, 2018).

Al-Othman (2009) defined e-learning as learning using electronic digital information devices and tools, including computers and the internet, whether in the classroom or via distance learning. Social networking websites have attracted the attention of young people around the world, as well as that of groups at different political, social, and economic levels (Namo, 2011; Ramadan, 2000). Social networking websites offer users a range of services, such as instant chat, private messaging, video sharing, file sharing, and others. The most popular global social networking websites are Facebook, Instagram, WhatsApp, Myspace, tagged.com, YouTube, and Twitter. Highley (1999) defined social networking as online social circles among friends who share their interests, including private and public topics such as writings, images, videos, chats, and acquaintances.

Social networks have positives effects such as: deepening the concept of sharing, communicating others, stimulating creative thinking and learning in different styles and methods. Communicating online with other people from different 
environments and cultures helps communicators accept contentious issues, activate their skills and achieve a good amount of entertainment (Namo, 2011). On the other hand, the issue of attitudes has occupied an important position in educational and psychological studies. However, it is acknowledged that measuring and evaluating human attitudes is not an easy or straightforward mission. Moreover, the attitudes regarding hypothetical characteristics lead to the need for finding effective measuring tools to evaluate the attitudes and their nature.

There are many criteria that can be used to select the items of measurement tools in general, and attitudes measures (Al-Nabhan, 2004). Many of these criteria stem from Classic Test Theory. Anastasi, as cited in (Gruijter \& kamp, 2005) posited that modern measurement theory or IRT, constitute a new and close scientific framework in the selection of items. They also address many educational and psychological issues more effectively than traditional theories. The IRT assumes that the performance of the examinees can be predicted, or their performance can be explained through psychological or pedagogical tests, in the light of the characteristics of this performance called trait. However, it is difficult to observe this attribute directly. Therefore, it must be assessed or inferred from the performance of the examinees, which can be observed on a set of scale or test items (Hambleton, Swaminathan \& Rogers, 1991).

Many models of modern measurement theory known as Latent Trait Models, (LTM) have been developed to identify and interpret the relationships between an individual's performances in test and characteristics that underlies this performance. Some of IRT models are based on basic assumptions such as: Unidimensionality, Local Independence, Item Characteristic Curve, ICC, and Speediness (Gruijter \& Kamp, 2005). One parameter model, which is called Rasch Model is one of the most popular used IRT models. The advantages that have given this model are that when the data correspond to this model, the parameters of the items which are difficult can be estimated independently of the sample used, and the capabilities of individuals can be estimated independently of the degree of difficulty of items (Hambleton, Swaminathan \& Rogers, 1991).

The Rasch model emerged from several models, each suiting a special type of data including: Dichotomous Model, Partial Credit model, Scale Rating Model. The later model is used in scale data which was developed by Andrich (Andrich, as cited in Wright \& Masters, 1982). The idea behind the scale ladder model is that each item carries a complete psychological burden that expresses the attitude of individual in accordance with his appreciation of that item, and the model estimates this shipment for each item according to the probability function adopted by the model. The only criterion with which the scale model is handled is by difficulty criterion in attitude measures. To detect the degree of match between items and scale ladder model, the researcher can use the statistical software (BIGSTEPS) to obtain quantitative data indicating how much an emotive charge of attitude, or measured attribute, carries data on at least a class scale. Furthermore, the software provides indications that sample individuals match the used form.

It is clear from the above, the importance of modern theory in measurement, what is known as IRT in building attitude metrics. As well as the importance of highlighting the concept of e-learning, and the attitudes of social media users towards e-learning. Despite the pedagogical literature in describing the different methods and procedures for building an attitude scale according to models of IRT, it did not receive much attention in research studies in the Arab world. The researchers found that most of the measures of attitudes used in Arabic studies were built according to concepts of traditional theory of measurement. The researchers were unable to access any study on what is known as e-learning. Therefore, the current study is distinguished from other studies, in that it is the first study based on our knowledge that seeks to build an attitudes scale towards e-learning among a sample of students at Isra University; This study is an attempt to provide an objective measurement tool in e-learning subject according to the modern theory of measurement models IRT. This is a potential area of research that has not been addressed in any previous study.

\section{Previous Studies}

Al-Momani \& Dlalah (2019) conducted many studies dealings with e-learning to reveal the reality of e-learning at the Middle East University from the viewpoint of the faculty members. The results of the study showed that the reality of using e-learning from the viewpoint of the faculty members at Middle East University was moderate. The results also showed that there are no statistically significant differences in the reality of using e-learning from the viewpoint of the faculty members at Middle East University was related to the impact of the variables of academic rank and gender. In another study, Hamad (2018), investigated the extent to which faculty members at Jordanian universities use e-learning tools in education and their attitudes towards applying them in teaching. The results of the study found that (86\%) of the faculty members used some e-learning tools in teaching, and (76\%) of the study sample did not use wiki, and there were no differences in the attitudes of faculty members due to gender, academic rank and university type.

While Al-Sharif (2016) conducted a study aimed at identifying the attitudes of Shaqra University students towards elearning. The results indicated that the students' attitudes towards e-learning were positive, and there were no statistically significant differences in students' responses to e-learning according to the variable of specialization 
(Scientific, Literary), while the results showed that there were statistically significant differences in students' responses to e-learning according to the gender variable (male, female) in favor of females. Abu Al-Sil (2016) conducted a study aimed at building a measure of achievement motivation for high school students at Damascus University according to the IRT. The most important results showed that the achievement motivation scale prepared by the researcher was onedimensional and the collected data matched the partial estimate model. Moreover, the results showed that the index of the average matching of individuals and the internal and external items approached zero, and the standard deviation approached one correct.

The study of Kandilingec (2015) aimed at determining the students' attitudes towards e-learning among students at technical and vocational secondary schools for girls and linking them to some variables. The study sample consisted of (119) students, where the researcher used the descriptive and analytical approach. The results of the study did not show any statistical significance differences between the attitudes of students from technical and vocational schools towards e-learning due to gender or experience.

\section{Problem of the Study}

The problem lies in appearance of a new educational form called e-learning as a result of technological revolution and its role in social life. Furthermore, this study is designed to meet the requirements for an accurate measurement tool to measure the students' attitudes towards e-learning in accordance to objective measurement criteria.

Many studies have shown positive impact of using the educational technology in students' achievement, such as study of Momani (2013), which has generated the need for researchers to develop an objective measure that measures the trends of students of the University of Isra towards e-learning, according to the IRT, which constitutes a new and close scientific framework in the selection of items at present, and it addresses many educational and psychological issues more effectively than the classical theory (Gruijter \& kamp , 2005). Hence, the current study aims to build a measure of trends towards e-learning in a sample of students at the University of Isra according to the modern theory of measurement. Taking into account the scientific trends related to the building of emotional metrics according to the IRT.

\section{Questions of the Study}

The current study seeks to answer the following research questions:

(1) To what extent do the data of this study match the items of the attitude scale towards E-learning among Isra university students according to IRT?

(2) What are implications of validity and reliability of the attitude scale towards E-learning among Isra university students according to the IRT?

\section{Population and Sample of Study}

The study population consisted of all students admitted to the bachelor's program at Al-Isra University for the academic year 2019/2020. The population of this study consisted of 1857 male and female students according to the annual statistical report at the Department of Admission and Registration at Al-Isra University. As for the study sample, it included (550) male and female undergraduate students at Al-Isra University who use the internet in their education, during the second semester of the academic year 2019/2020. The sample was chosen in a simple random method, as (550) questionnaires were distributed, while several questionnaires were lost during the application period. Only 13 questionnaires were not submitted which were $(2.36 \%)$ of the sample.

Moreover, the researchers excluded several response papers on the research tool due to the lack of data in them which were (21) questionnaires (3.82 of the sample. Therefore, the number on which the analysis was performed reached (516) questionnaires $(93.82 \%)$ of the total sample. Table 1 shows the distribution of the members of the study sample in terms of the distributed numbers, the missing numbers, the excluded numbers, and the final numbers on which the analysis was carried out.

Table 1. the sample details

\begin{tabular}{ccccccccc}
\hline \multirow{2}{*}{ Variable } & \multicolumn{2}{c}{ Distributed } & \multicolumn{2}{c}{ lost } & \multicolumn{2}{c}{ Excluded } & \multicolumn{2}{c}{ Remaining } \\
& Number & $100 \%$ & Number & $100 \%$ & Number & $100 \%$ & Number & $100 \%$ \\
\hline Male & 470 & $85.45 \%$ & 8 & $1.45 \%$ & 10 & $1.82 \%$ & 452 & $82.18 \%$ \\
Female & 80 & $14.55 \%$ & 5 & $0.91 \%$ & 11 & $2 \%$ & 64 & $11.64 \%$ \\
Total & 550 & $100 \%$ & 13 & $2.36 \%$ & 21 & $3.82 \%$ & 516 & $93.82 \%$ \\
\hline
\end{tabular}




\section{Procedure}

For the purposes of the present study, a measure of attitudes toward electronic violence was constructed, according to the IRT following Hulin, Drasgow \& Parsons (1983), as follows:

\subsection{Reviewing the Literature and Previous Studies Related to the Topic of Trends:}

The process of measuring trends is difficult as they are hypothetical traits in nature. Thus, there is a need for effective metrics to measure trends that emerge. In trend scales, the researcher is primarily interested in compiling a list of expressions that cover all possible opinions regarding the concepts under investigation. So that each statement is clear and concise, and focuses on feelings rather than facts, and on the same direction instead of information (Thorndike and Heigen, 1989).

The researchers have benefited from previous literature on this topic, including the questionnaire developed by (AlMomani \& Dalalah, 2019), which aimed to uncover the reality of e-learning in the Middle East University from the faculty members' point of view. As well as the questionnaire developed by Hamad (2018) that aimed to measure the degree to which faculty members at the Jordanian universities use e-learning tools in education and their attitudes towards them, and the tendency scale used by Al-Shannaq and Bani Domi (2010) to measure the attitudes of students and teachers towards e-learning, and the scale that Al-Aisan and Al-Ani (2007) used by developing a questionnaire to identify the reality of e-learning from the viewpoint of students of the College of Education at Sultan Qaboos University in order to find out the advantages and disadvantages of e-learning. Also, the scale used by Al-Dalalah (2009) by testing the knowledge outcome according to the IRT. And the benefit from the study presented by Al Dalalah (2011) regarding the effect of multiple-choice items shape and the level of ability of individuals on the accuracy of estimates for the parameters of the items and individuals according to the IRT.

\subsection{Determining the Scale Dimensions:}

This step is one of the most important steps in building the attitude scales. After reviewing a number of studies, articles and books in the field of attitudes towards e-learning, the researchers were able to identify the main attitudes towards e-learning, which could be included in following three main dimensions:

(1) Attitudes towards the concept of e-learning.

(2) Attitudes towards the reasons for using e-learning.

(3) Attitudes towards e-learning requirements.

\subsection{Procedural Drafting of the Scale Items:}

The researchers have benefited from the suggestions made by Al-Nabhan (2004) and (Hendcson, et al., 1987) related to constructing the attitudes scales. The main point was writing the scale items using directional terms that control all directions except for the direction to be measured, and checking each key word, especially nouns and adjectives. The application of the scale in the natural environment of individuals by the person concerned with the measure and conduct an exploratory study to examine the phrases. When drafting the scale items, the following was taken into consideration:

(1) Avoiding the use of phrases that refer to the past.

(2) Avoiding the use of statements that express facts or can be interpreted as facts.

(3) Avoiding the use of phrases that can be interpreted in more than one way.

(4) Using simple, clear language and avoid unintelligible words.

(5) The item should include one simple idea.

(6) Avoiding the use of sentences and phrases that contain double negation.

(7) Avoiding the use of generalizations such as: always, never, all, and not.

(8) Be careful when using words like only, and just.

Depending on the previous steps, the researchers were able to formulate (44) items that included the previous three dimensions, and they were of the five-dimensional Likert type, which is one of the most used measures. For the ease of design, application and correction, the researchers took into account that the distribution of items is negative, positive and random. So that the subject does not know the general direction of the subject to be measured. According to this scale, the subject's response on each statement is transformed into estimated weights ranging from 1-5. In the case of the five response alternatives: the score (1) is given for the response "strongly disagree", the score (2) for the response "disagree", and the score (3) for the response "neutral", the score (4) for the response "agree", and finally the 
score (5) for the response "strongly agree", in the case of the positive statements. On the other hand, the negative statements are corrected in the opposite direction of the previous scoring.

\subsection{Applying the Scale}

\subsubsection{Testing the Scale on A Pilot Sample}

The scale that consisted of 44 items was presented to (25) judges who hold a $\mathrm{PhD}$ in educational psychology, measurement and evaluation, curricula and teaching methods. For the purpose of verifying the clarity and wording of the items, the extent to which the item belongs to the dimension and the scale, and the extent to which it conforms to the criteria for drafting the direction items, and to suggest any amendments, or any items that would increase the coverage of the items of the scale of the trend towards electronic violence. Based on the judges' observations, the wording of some items has been amended, and some items have been deleted in which there was a consensus between the judges' opinions regarding their weaknesses. However, some items were merged in accordance to the judges' opinions. Therefore, the scale was formed in its initial form of (31) items distributed on the three dimensions unevenly. Appendix shows the distribution of the items on the three dimensions.

After the scale was prepared in its initial form (31 items), it was applied on an exploratory sample consisting of (95) male and female students who use the internet in their education and learning. After collecting the questionnaires, there were some observations about some items that were taken into consideration, and some amendments were made to the items that their responses were extreme. At this stage, none of the items belonging to the three dimensions of the scale were deleted, as the scale items were preserved in its initial form (31) items, as shown in Appendix.

The reliability coefficient was extracted by the method of repetition using the Pearson-Correlation coefficient with a difference of three weeks between the first application and the second application. The value of the reliability coefficient was as shown in Table 2 .

Table 2. result of reliability coefficient

\begin{tabular}{lcccc}
\hline Dimension & $\begin{array}{c}\text { The attitude towards e- } \\
\text { learning concept }\end{array}$ & $\begin{array}{c}\text { The attitude towards } \\
\text { reasons for using e- } \\
\text { learning }\end{array}$ & $\begin{array}{c}\text { The attitude towards e- } \\
\text { learning requirements. }\end{array}$ & Total \\
\hline $\begin{array}{l}\text { Reliability } \\
\text { coefficient }\end{array}$ & 0.83 & 0.80 & 0.74 & 0.86 \\
\hline
\end{tabular}

\subsubsection{Applying the Scale to the Study Sample}

The scale was applied to (550) undergraduate students at Al-Isra University who use the internet for education, during the second semester of the academic year 2019/2020. The participants were randomly selected from the study population in order to get the largest possible number of internet users in education (the subjects). The remaining (516) students represented the participants of the study by using the one-parameter logistic model (Rush model) in the IRT, as the study needed at least 200 subjects per group (Crocker \& Algina, 1986).

\section{Statistical Treatment}

To answer the research questions, data related to the responses of the study sample (516) male and female students were entered into a computer using the SPSS statistical software to verify the Unidimensionality assumption. Whereas, modern statistical software (Bilog-MG3) and (BIGSTEPS) were used to reveal the conformity of the study data about the items of the measure of attitudes of study sample towards e-learning using the model of the scale of estimation, and to study the psychometric properties of its items that were freed from individuals based on the same model.

\section{Finding and Discussion}

RQ1: The results related to the extent of matching between the collected data according to the items of the attitude scale of the sample that use the internet in education towards e-learning according to the IRT.

Prior to answering this question, the assumption of Unidimensionality must be verified. Where the IRT models assume the existence of a single ability that explains the performance of the subject on the scale, and therefore it is called onedimensional models. To verify this assumption, a global analysis of the scale data related to the responses of (516) students who use the internet in education at Al-Isra University was conducted for the (31) items, using the SPSS statistical software.

The results of the factor analysis procedure were extracted by Principle Components Analysis (PCA) method and rotating according to orthogonal axes (Varimax). Where the analysis produced (12) factors, the first factor explained 
$15.817 \%$ of the variance, and all factors explained $52.736 \%$ of the total variance. Table 3 shows the values of the eigenvalues, the ratio of the explained variance for each factor, as well as the cumulative interpreted variance ratio.

Table 3. eigenvalues, explain ratio and cumulative variance

\begin{tabular}{cccc}
\hline Factor & Eigenvalues & Variance explained \% & Accumulative variance \% \\
\hline 1 & 5.562 & 15.817 & 15.817 \\
2 & 1.921 & 3.991 & 19.808 \\
3 & 1.632 & 3.924 & 23.732 \\
4 & 1.541 & 3.715 & 27.447 \\
5 & 1.420 & 3.628 & 31.075 \\
6 & 1.353 & 3.577 & 34.652 \\
7 & 1.318 & 3.399 & 38.051 \\
8 & 1.214 & 3.160 & 41.211 \\
9 & 1.167 & 3.015 & 44.226 \\
10 & 1.158 & 2.893 & 47.119 \\
11 & 1.135 & 2.811 & 49.930 \\
12 & 1.096 & 2.806 & 52.736
\end{tabular}

It can be seen from Table 3 that the eigenvalues of the first factor amounted to 5,562 and explains $15,817 \%$ of the total variance, which is a high value if compared with the values of the latent roots of the rest of the factors. While the value of the latent root of the second factor amounted to 1.921 and explains $3.991 \%$ of total variance, meaning that the first factor explained more than twice as much as the second factor. In addition, it is noted that the ratio of the variance explained for each of the remaining factors is close, meaning that there is a quasi-stability in the proportions of the variance explained for all factors except for the first factor. Hence, this is an indication of the fulfillment of onedimensional assumption of the scale (Hulin, Drasgow \& Parson, 1983; Hattie, 1985). That is, the scale measures a only single characteristic. The one-dimensional assumption of the scale prepared in the current study is strengthened by graphically representing the latent roots using what is known as the Scree plot, which is shown in Figure 1, which shows the graphic representation of the values of the underlying roots of the factors composing the scale on the total data.

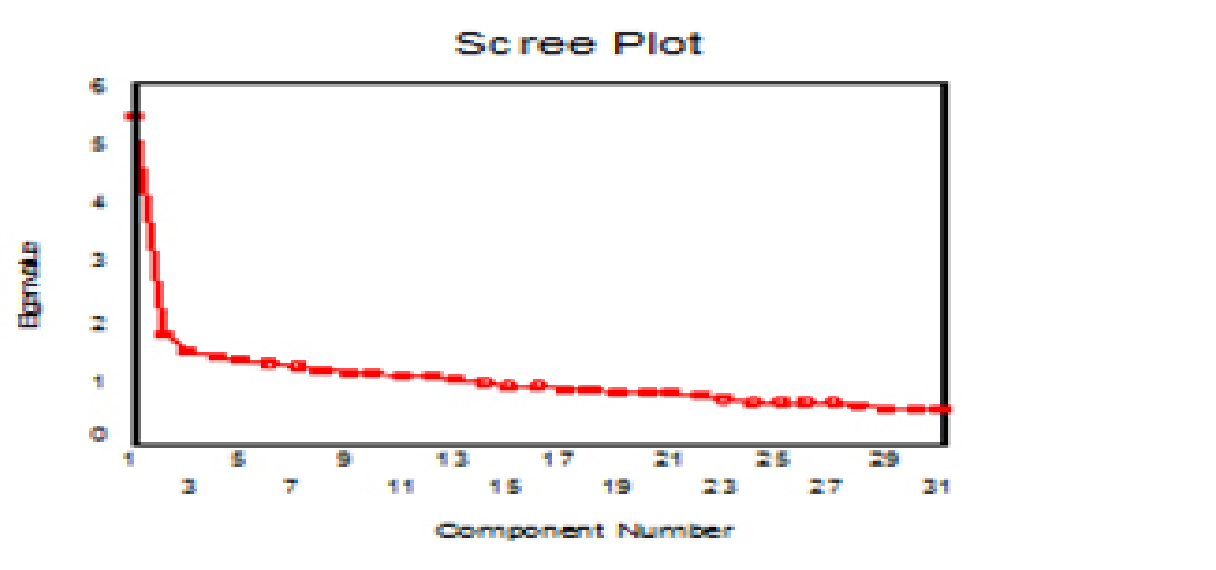

Figure 1

It can be seen from Figure 1, that the eigenvalues of the first factor clearly overrides the latent roots of the rest of the factors, and this is also an indication of one-dimensional data for the scale.

To verify the assumption of (Goodness-of-Fit-Test) of the responses of the scale items according to the scale model: the data were subjected to analysis using the statistical software (BIGSTEPS). Where data on the response of the study individuals (516) male and female students were entered on the items of the e-Learning attitudes scale, consisting of (31) items according to Likert's five-scale grading, and the results were extracted according to this software program according to the following steps: 
A- Identifying the indicators of conformity of individuals (Persons- Fit): In order to define the matching indicators of individuals, the ability of everyone was estimated, in addition to the standard error in measuring this ability. The internal matching statistic (INFIT), which is a statistical indicator of unexpected behaviors that affect responses to items that are close to a certain ability level was also calculate. In addition to an external match statistic (OUTFIT) computed for each of these estimates, which is a more sensitive indicator of behaviors. Persons are not expected to report items that depart from their level of ability which contains similar characteristics to the previous statistician (INFIT).

Table 4 below shows the arithmetic mean and standard deviation for each estimate of the capabilities of individuals, the standard error in measuring this ability (MODEL ERROR), the means of squares for the internal and external match statistics (Mean Square Infit Statistic, MNSQ), and the values of the match statistics for the internal and external match statistics (The Standardized Information Weighted Fit Statistics for Persons, ZSTD).

Table 4. mean and standard deviation for each estimate of the capabilities

\begin{tabular}{ccccccc}
\hline & \multirow{2}{*}{ ability } & $\begin{array}{c}\text { Standard } \\
\text { error }\end{array}$ & MNSQ & ZSTD & MNSQ & ZSTD \\
\hline $\begin{array}{c}\text { Mean } \\
\text { Standard }\end{array}$ & 0.34 & 0.28 & 1.05 & $0.1-$ & 1.03 & $0.2-$ \\
deviation & 0.87 & 0.04 & 0.53 & 1.3 & 0.72 & 1.2
\end{tabular}

It can be seen from Table 4, that the arithmetic means of the internal and external MNSQ averages amounted to (1.05) and (1.03) respectively, meaning that it approaches one, which is the ideal situation as expected by the model. It also appears that the average of the values of the internal match statistic has reached (-0.1) and its standard deviation is (1.3). It is also close to the ideal values suggested by the model, which are $(0,1)$, respectively. It was also found that the average of the values of the external match statistic reached (-0.2), and its standard deviation was (1.2). It is also close to the ideal values suggested by the model, which are ( 0 and 1$)$, respectively. When examining the values of the weighted external match statistic for individuals, it was found that there are (29) individuals whose observed responses deviated from the expected responses according to their abilities, meaning that the average values of the squares corresponding to their abilities exceeded one correct, or that the values of the external match statistic corresponding to their abilities exceeded (+2). As Alastair \& Hutchinson (1987) pointed out, if the value of this statistic is greater than $(+2)$, the ability of the individual is not identical with the abilities of the group of individuals. So, these individuals do not match the model, and they must be excluded to complete the analysis.

B- After excluding the twenty-nine individuals whose responses and expectations of the model did not match, the analysis was repeated to test the extent to which the scale items matched the model (Item-Fit). The difficulty parameter was estimated for each item, the standard error in measuring this parameter, the internal match statistic, in addition to the external match statistic for each difficulty parameter. Table 5 shows the arithmetic mean and the standard deviation for each of the estimates of the difficulty parameters and the standard error in measuring these estimates, in addition to the statistics of the internal and external conformity of the items.

Table 5. results of the estimates of parameters, standard error, INFIT and OUTFIT

\begin{tabular}{ccccccc}
\hline & \multirow{2}{*}{ Difficulty } & $\begin{array}{c}\text { Standard } \\
\text { error }\end{array}$ & MNSQ & ZSTD & MNSQ & ZSTD \\
\hline Mean & 0.00 & 0.08 & 1.00 & $0.1-$ & 0.97 & $0.2-$ \\
$\begin{array}{c}\text { Standard } \\
\text { deviation }\end{array}$ & 0.72 & 0.01 & 0.14 & 1.3 & 0.13 & 1.4 \\
\hline
\end{tabular}

It can be seen from Table 5 that the mean of the averages of the squares were close to one true, which is the ideal situation as expected by the model. It also appears that the average of the values of the internal match statistic has reached (-0.1), and its standard deviation is (1.3). It is also close to the ideal values that the model assumes, which are $(0$ and 1$)$, respectively. It was also found that the average values of the external match statistic reached $(-0.2)$ and the standard deviation thereof reached (1.4). It is also close to the ideal values assumed by the model.

When examining the values of the internal and external matching statistic for the items scale in its initial form (31) items, it was found that there are two items, one of which exceeded the values of the corresponding statistic $(+2)$, and the other exceeded the average values of the squares for which the one is correct. This is an indication that they are 
non-conforming items to the model expectations (Linacre \& Wright, 1993). They are the two items with serial numbers 7 and 15 , and therefore were excluded from the analysis.

C- After removing the two non-conforming individuals and the two items that do not conform to the model expectations, the analysis was re-analyzed for the third time - using the same program - to obtain a final liberal estimate of both the difficulty of the factor of the items and the capabilities of the individuals. Table 6 below shows the results of the analysis of the freed values of the capabilities of individuals.

Table 6. the final estimates of the capabilities of individuals

\begin{tabular}{ccccccc}
\hline & \multirow{2}{*}{ ability } & Standard & \multicolumn{2}{c}{ INFIT } & \multicolumn{2}{c}{ OUTFIT } \\
& error & MNSQ & ZSTD & MNSQ & ZSTD \\
\hline $\begin{array}{c}\text { Mean } \\
\begin{array}{c}\text { Standard } \\
\text { deviation }\end{array}\end{array}$ & 0.35 & 0.30 & 1.03 & $0.09-$ & 1.02 & $0.1-$ \\
& 0.93 & 0.04 & 0.27 & 1.1 & 0.74 & 1.09
\end{tabular}

It can be seen from Table 6 that the average distribution of the final estimates of the capabilities of individuals amounted to (0.35) Logit units, and the standard deviation was (0.93) Logit units, which is close to the ideal situation assumed by the model. In addition to be a low value, it indicates the accuracy of determining the individual location on the attribute scale.

It can be seen from Table 7, that the average values of the liberalized estimates of the difficulty of the items are distributed by an arithmetic mean of zero logs and a standard deviation of (0.72) Logit units, which is close to the ideal position assumed by the model, which indicates the accuracy of estimating the difficulty of the items, meaning that there is a kind of consistency in the gradation of the difficulty of the items, and that the scale measures an acceptable range of abilities.

Table 7. liberalized estimates of the difficulty of the items

\begin{tabular}{ccccccc}
\hline & \multirow{2}{*}{ Difficulty } & $\begin{array}{c}\text { Standard } \\
\text { error }\end{array}$ & MNSQ & ZSTD & MNSQ & ZSTD \\
\hline Mean & 0.00 & 0.08 & 1.00 & $0.1-$ & 0.97 & $0.17-$ \\
$\begin{array}{c}\text { Standard } \\
\text { deviation }\end{array}$ & 0.72 & 0.01 & 0.18 & 1.02 & 0.16 & 1.3
\end{tabular}

RQ2: The results related to the indications of validity and reliability of the attitudes measurement of a sample of internet users at Isra University towards e-learning based on the IRT:

It was verified that the scale measures the attitudes of the sample of internet users in education towards e-learning, which was designed to measure through theoretical analysis of the concept of e-learning, and by identifying the dimensions that fall under it through identifying the items, their formulation, and the method of judging them. Pearson correlation coefficients were calculated between performance on the scale and its dimensions on the one hand, and Pearson correlation coefficients between performances on the scale dimensions with each other on the other hand. Table 8 shows the values of those parameters for the scale in its final form (29) items, and its various dimensions which measure the attitudes of a sample of internet users at Isra University towards e-learning.

Table 8. Pearson correlation coefficients between performance on the scale and its dimensions.

\begin{tabular}{ccccc}
\hline Dimension & First & Second & Third & Total \\
\hline First & & $* 0.81$ & $* 0.74$ & $* 0.67$ \\
Second & & & $* 0.68$ & $* 0.68$ \\
Third & & & & $* 0.62$ \\
\hline
\end{tabular}

Sig at $(\alpha<0.01) *$

It can be seen from Table 8 that the values of the Pearson correlation coefficients between performance on the scale and its dimensions, as well as the Pearson correlation coefficients between performance on the scale dimensions with each other, were all close, and its statistically significant at the level of $\alpha<0.01$. The internal consistency coefficient of stability of the scale items was also calculated, in its final form consisting of (29) items, using the Cronbach alpha 
equation, reaching (0.92), using the SPSS software. This result indicates that the scale has an acceptable degree of reliability.

Among the other indicators from which indicates the reliability factor of the scale according to the modern theory of measurement is inferred through information function. The curve of information function of the scale results is formed by the compilation of the curves of the items on according to the following relationship:

$$
\mathrm{I}(\theta)=\sum \operatorname{Ig}(\theta)
$$

Where I $(\theta)$ is the amount of information for the scale at the power level, and $\sum \operatorname{Ig}(\theta)$ is the sum of the information functions of the scale items at the power level. Therefore, increasing the number of items gives a small standard error and decreasing the value of the standard error in estimating the power $\theta$ leads to increase the amount of information provided by the scale according to the following relationship: Therefore, decreasing the value of the standard error in estimating the power leads to an increase in the value of the reliability factor.

$$
\mathrm{I}(\theta)=\frac{1}{\sqrt{\operatorname{S.E}(\theta)}}
$$

What distinguishes the IRT from the traditional theory of measurement is that the estimation of stability in the traditional theory is related to the sample, while the IRT provides us with an estimate of the standard error of the measurement at each level of power, and through which it is possible to determine the extent of each item contribution to determining the accuracy of the measurement. To implement this, the statistical software (Bilog- MG3) was used to estimate the amount of information for the scale at each of the specified levels of ability, and to draw the relationship between the values of the information function and the standard error of the scale items, as shown in Figure 2. The Figure shows the scale information function and the standard error of estimation for its items according to the modern theory of measurement.

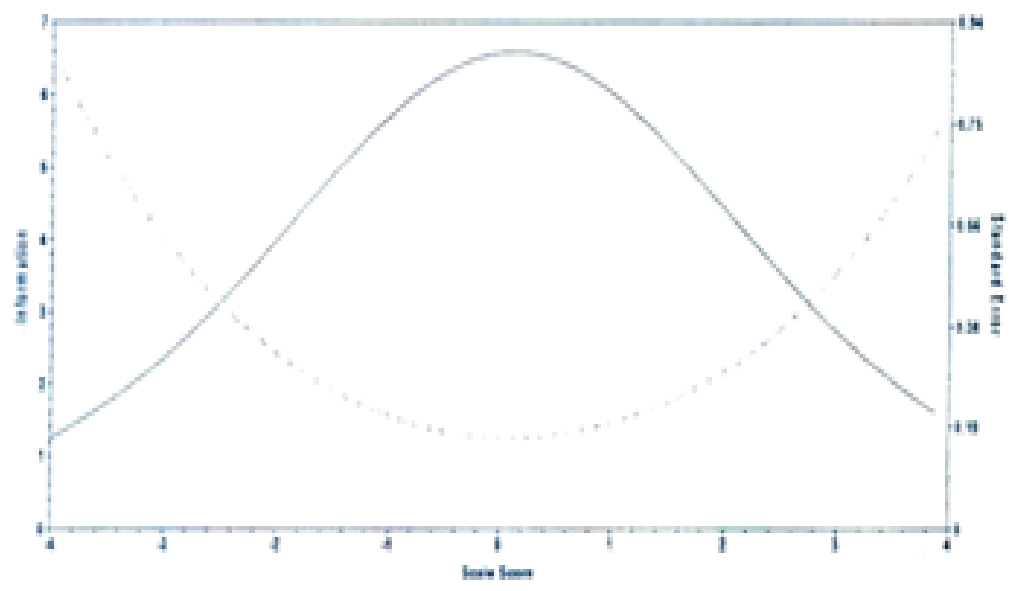

Figure 2

Connected curve: represents the indication of information.

Disconnected curve: represents the standard error.

It is noticed from Figure 2, that the largest amount of information provided by the scale was at medium capacity, while it is noticed that the least amount of information provided by the scale was at high and low capacity levels. This would mean that the scale gives less information about individuals with positive and negative attitudes. The results showed that the highest amount of information function provided by the test was 6.411 , while the maximum value of the information function for each item was 0.125 . In addition, it is noticed that the amount of information provided by the scale increases with the decrease of the standard error of the estimate, and this is consistent with the expectations of the scale model according to the theory of item response.

Moreover, the reliability of the scale was verified using the statistical software (BIGSTEPS), which gives two estimates of the reliability coefficient, namely: the scale stability, and the reliability of individuals. Where the value of the Item 
Separation Index was 6.94, while the value of the Person Separation Index was 2.41, and both values exceeded (2) (Wright \& Masters, 1982). This result means that the scale reliability coefficient reached (0.94), and the index of stability of individuals reached (0.86). Undoubtedly, these values are high values and indicate the adequacy of the scale items in separating individuals. The distinction between the different levels of ability of individuals on one hand, and the adequacy of the individual's sample in separating between the scale items and the definition of the characteristic continuum which items measure on the other hand. In a more precise sense, individuals are distributed appropriately on the attitudes connected to the items of the scale of attitudes of a sample of internet users in education at Al-Isra University towards e-learning that was built according to the IRT.

In any case, the reliability coefficient of the attitudes scale based in the current study according to the IRT was higher than the coefficients of reliability computed for attitudes scales in some previous studies, such as the (Polichnowski, 2008) and (Dimond et al., 2011), (Abdullah and Abu Fakhida, 2009), and (Al-Ghamdi, 2009).

\section{Recommendations for Future Research}

In light of the findings of the current study, researchers recommend the following:

1. Using the scale in its final form, of 29 items, to reveal the attitudes of social media users towards e-learning; Given that the scale based on and conforming to the expectations of the estimate scale model of IRT has acceptable indications of validity and reliability.

2. Conducting more studies on the initial image of the scale designed in the current study by using different latent features models. In addition to making a comparison between them and applying it to include other universities to confirm confidence about the validity and reliability of the scale in revealing the attitudes of internet users in university education towards e-learning.

3. Relying on the statistical software used in the current study (SPSS \& BIGSTEPS \& Bilog-MG3) in building the attitudes scales according to the items IRT and trying to benefit from other indicators provided by this software in building attitudes measurements.

\section{References}

Abdullah, T., \& Abu Fakhida, J. (2009). Al-Quds University Students' Attitudes towards University Violence, Journal of the Union of Arab Universities for Education and Psychology, 52, 549-599.

Abu Al-Sil (2016). Building an achievement motivation scale for high school students in Damascus according to the item's response theory, Journal of the Union of Arab Universities for Education and Psychology. Volume 14, Issue 4, 140-176.

Al-Aisan, S., \& Al-Ani, W. (2007). E-Learning from Students' View Points in College of Education in Sultan Qaboos University, Journal of Educational Science studies, Volume 34, Issue 2.

Al-Dlalah, M. (2011). The Effect of format of Multiple-Choice Items Structure and Persons Ability Level on the Accuracy of Person and Items Parameter Estimations According to the Item Response. Faculty of education Journal, Al-Mansoura University, third issue.

Al-Dlalah, M. (2018). Development and legalization of cognitive outcome scale according to Items response theory in measurement. Yarmouk Research Journal: Humanities and Social Sciences Series, Issue 2, Volume 25.

Al-Ghamdi, M. (2009). The relationship between family violence, and school violence, tested on a sample of intermediate stage students in Jeddah, Unpublished master thesis, Um al-Qura University, Mecca.

Al-Momani, T., \& Dlalah, M. (2018). The effect of using formative tests on the achievement of basic seventh grade female students in mathematics, Transylvanian Review, Vol XXVI, No.27.

Al-Momani, T., \& Dlalah, M. (2019). The Reality of Using E-Learning at the Middle East University from its Faculty Members' Point of View. accepted for publication in International Collaboration for Research \& Publication (ICRP), Vol. 35. Special Edition No.22.

Al-Nabhan, M. (2004). Basics of Measurement in Behavioral Sciences, First Edition, Al Shorouq Publishing and Distribution House, Amman.

Al-Othman, M. (2009). An analytical study of master's and Ph.Ds. thesis in e-learning area, at King Saud University in Riyadh during the period time 1414 to 1427 Hijri. Unpublished master thesis, King Saud University, Riyadh.

Al-Shannaq, Q., \& Bani, D. H. (2010). The attitudes of teachers and students towards using e-learning in Jordanian secondary schools, Journal of Damascus University, Volume 26, Issue (1+2). 
Al-Sharif, M. (2016). The students' attitudes in Shaqra University towards e-learning, Faculty of Education Journal, Al-Azhar University Issue (168, Part 3).

Dimond, J., Fiesler, C., \& Bruckman, A. (2001). "Domestic violence and information communication technologies", Interacting with Computers, 23(5), 413-421. https://doi.org/10.1016/j.intcom.2011.04.006

Gruijter, D., \& Kamp, L. (2005). Statistical Test Theory for Education and Psychology, Retrieved December 30, 2005, from: www.leidenuniv.nl/-gruijterdnmde.

Hamad, L. (2018). The degree of using e-learning tools in teaching by faculty staff members in Jordanian universities and their attitudes toward it, Unpublished master thesis, Middle East University, Jordan.

Hambleton, R., Swaminathan, H., \& Rogers, J. (1991). Fundamental of Item Response Theory, Second Edition, Newbury Perk California.

Hattie, J. (1985). "Methodology review: assessing Unidimensionality of tests and items", Applied Psychological Measurement, 9(2), 139-164. https://doi.org/10.1177/014662168500900204

Hendcson, M., I., \& Fitz-Gibbon, C. (1987). How to Measure Attitudes, First Edition, Sage Publications, Newbury Park.

Highley, R. (1999). Viruses, the Internet Illness [Online], Available: https://www.chemistry.vt.edu/chemdept/dessy/honors/papers99/highleh.htm

Hulin, C., Drasgow, F., \& Parsons, C. (1983). Item Response Theory: Application to Psychological Measurement, First Edition, Dow Gone-Irwin.

Kandillngec, S. (2015). Investigation of Student' Attitudes Towards E-Learning in Terms of Different Variables - A case Study. Technical and Vocational High School for Girls Educational Research and reviewed, 10(1), 81-91. https://doi.org/10.5897/ERR2014.1980

Momani, T. (2013). The effect of using educational computer on students' achievement in the mathematics methods course at Hail University for girls, Journal of the Union of Arab Universities, Amman, Volume (33), Issue4.

Namo, A. (2011). Twitter, Facebook and YouTube's Role in Arab Spring (Middle East Uprisings), [Online], Available: https://socialcapital.wordpress.com/uprising

Polichnowski, E. (2008). "adaptive through spiritual well-being as a mediator or moderator of the relationship to the adverse psychological effects of dating violence in sample of university students" (Dissertation and Theses) John Hopkins University, Baltimore, Maryland.

Ramadan, M. (2000). Crimes of assault on people and the Internet. Arab Renaissance House, Cairo.

Shahada, A. (2006). The Educational technology, Dar Konooz-Almarefa Publishing \&Distribution.

Wright, B., \& Master, G. (1982) Rating Scale Analysis. Rasch Measurement, First Edition, MESA Press, Chicago. 


\section{Appendix}

\section{A scale of attitudes towards e-learning}

The researchers are conducting a study aimed at building a scale of attitudes towards e-learning among Isra university students following the Item Response Theory in Measurement. To achieve the objective of the study, please answer the following question:

Do you use the internet in your learning?

Yes No

If your answer is (No), kindly submit the questionnaire.

If your answer is (Yes), please kindly answer all of questionnaire items by writing ( $\mathrm{x}$ ) in front of each item that expresses your attitude towards e-learning, below the five options (I strongly agree, Agree, Neutral, I disagree, I strongly disagree).

Personal information:

Sex: $\quad$ Male

Female.

Thanks for your cooperation.

\begin{tabular}{|c|c|c|c|c|c|c|}
\hline No. & The first dimension: the concept of e-learning & $\begin{array}{c}\text { Strongly } \\
\text { agree }\end{array}$ & Agree & Neutral & disagree & $\begin{array}{l}\text { strongly } \\
\text { disagree }\end{array}$ \\
\hline
\end{tabular}

1. E-learning is a type of indirect education.

2. E-learning is a method to improve the learning outcomes.

3. I have information about e-learning concept.

4. Full e-learning eliminates the direct relationship between teacher and student.

5. E-learning complements the traditional teaching methods.

6. E-learning supports students self-learning.

E-learning enables students to learn anytime and anywhere, which reduces the economic cost of education.

8. The information provided by the websites of the faculty members increases students' learning skills.

9. All materials must be converted electronically with the addition of some visuals and audio to the course.

10 E-learning helps raise the level of students academically.

E-learning helps change educational curricula according to future needs.

12 I am satisfied with the extent of my information about the elearning system.

\section{The second dimension: Reasons for using e-learning}

13 E-learning is essential for every faculty member at university.

14 E-learning programs are interesting.

$15^{*} \quad$ E-learning is one of the primary methods of teaching.

16 E-learning enables students to learn a lot of information in a short time.

17 E-learning helps in developing creative skills.

18 E-learning stimulates students to think creatively. skills. 
E-learning increases the effectiveness of students in the lecture.

21 E-learning hinders faculty members' work on campus.

22 E-learning adds a burden on the faculty member at university.

23 The usual teaching methods give better results than the electronic teaching method.

\section{The third dimension: E-learning requirements}

$24 \quad$ Providing enough computers for all students.

25 Lack of training courses for students to acquire skills in dealing with e-learning websites.

26 Frequent network malfunctions obstruct entry to the site.

27 Providing an educational guide for guidance on how to use elearning programs.

28 Student sitting for a long time in front of the computer affects their health.

29 The opportunity for actual experimentation is almost nonexistent in e-learning.

30 The e-learning process lacks human touch.

$31 \quad$ Poor computer skill.

\section{Copyrights}

Copyright for this article is retained by the author(s), with first publication rights granted to the journal.

This is an open-access article distributed under the terms and conditions of the Creative Commons Attribution license (http://creativecommons.org/licenses/by/4.0/). 